\title{
The Communication Imperative in Resolving Communal Clashes in Ebonyi State, Nigeria
}

\author{
Allen Nnanwuba Adum \\ Department of Mass Communication, \\ Nnamdi Azikiwe University, Awka, \\ Anambra State, Nigeria \\ Emeka Odogwu \\ Department of Mass Communication, \\ Nnamdi Azikiwe University, Awka, \\ Anambra State, Nigeria \\ Kobimdi Umeh \\ Department of Mass Communication, \\ Nnamdi Azikiwe University, Awka, \\ Anambra State, Nigeria \\ Chinelo Ezeanyanwu \\ Department of Mass Communication, \\ Nnamdi Azikiwe University, Awka, \\ Anambra State, Nigeria
}

\begin{abstract}
The media as the fourth estate of the realm is susceptible to manipulation; regardless of place and time. This is partly why media-conflict study is gaining currency, globally. The communication imperative in resolving communal clashes in Ebonyi State is now of concern to both peace and conflict scholars and public policy makers. The kind of information the media disseminate is critical to sustaining peace and harmony in the society. It is on this note that we examined the role of the communication imperative in resolving communal clashes in Ebonyi State. To what extent has the mainstream media shunned the principle of 'who pays the piper dictates the tune'; a tendency that promotes and escalates conflict or communal clashes in the society, and concentrates on the issues fueling the conflict in order to get the government to respond to the grievances of the people before it degenerates into conflict? Using desk research, the paper argues that the communication imperative is vital in promoting peace and resolving communal clashes by embracing the principle of peaceful coexistence as against the policy of disseminating only the kind of information those who pay their wages want them to. The latter often tends to instigate and escalate conflicts, as empirical evidence has demonstrated in other parts of Nigeria and other flashpoints across the globe.
\end{abstract}

Key words: Communal clashes, communication imperative, media-conflict study, flash-points

DOI: $10.7176 / \mathrm{PPAR} / 9-6-12$

Publication date:June $30^{\text {th }} 2019$

\section{INTRODUCTION}

The link between resource and conflict is exemplified in Ebonyi State of Nigeria. The two local government areas of Ikwo and Abakaliki, in Ebonyi State, are richly endowed with lead deposit. Before the discovery of lead in 1925, the mainstay of the local economy was hunting and farming, but all that have been dislocated by lead exploration and exploitation activities. This is partly what has created the fault lines for perennial conflicts over lead in the Area. Thus, the role of lead in Ikwo and Enyigba conflict is paradoxical: while the expatriate and state government enjoy the revenue accruing from lead exploitation, communities in the area endure the consequences of lead exploration and exploitation such as several forms of ecological disaster. Narrating the negative impact of lead producing communities, Oshita and Osaze (2010) observed that: destroyed wild life rendered hunters unemployed. Acres of arable land have been destroyed along the livelihoods of famers and families. Houses are pulled down owing to erosion degradation. The cumulative effects of these are poverty, hunger, disease, illiteracy and severely fractured cognition for generations. Worse still, there is a dearth of good schools for the children. Scarcity of potable water precipitates conflict over water ponds and land.

Communities, non-state actors and most recently unlawful groups have protested against the foregoing conditions using both constitutional and unconstitutional means in the attempt to draw the attention of successive 
governments. In response, the state government had resorted to the use of repressive policy and the tactics of playing one community against the other, thereby instigating and intensifying inter and intra communal conflicts in the state. The failure of the state government to address the need-based grievances of communities was the main causes of conflict in Ikwo and Abakaliki local government areas.

Several intervention programmes initiated by government agencies such as Oil Mineral Producing Areas Development Commission (OMPADEC) and Ebonyi State Development Commission have not averted the underlying grievances. The immediate and remote causes of the Ikwo and Enyigba crises have been politicized along political party lines. Those inclined to the ethnic thesis believe that the crisis is a classic case of ethnic and political cleansing. The media may also have lost interest in keeping abreast with development in Ebonyi State. At best, the incidents are reported merely to keep the account of happenings and not to draw any more attention to these incidents.

\section{HISTORICAL OVERVIEW OF EBONYI STATE}

Political history of the geo-political entity presently known as Ebonyi State (old Abakaliki and Afikpo Divisions) dates back to 1906 when they were joined together in the old Ogaja province and later into Abakaliki province in 1959. Then the psychological concept or social stigma attached to the people of the area was both derogating and maligning.

The people were described derogatorily as poor and short of creative memory. Indeed the Ebonyi people were the victims of the "divide and rule system, and injustice in its worst operative form.

Ebonyi State is inhabited by an ethnic group of people with common cultural heritage, identical political and cultural affirmity. Geographically, Ebonyi area comprises of the old Abakaliki and old Afikpo Divisions with a land mass of 5,935.6 square kilometers and presently divided into thirteen local government areas with three senatorial zones, namely Ebonyi North zone, Ebonyi Central zone and Ebonyi South zone.The people are homogenous and well integrated socially, culturally, and economically. Ebonyi State created $1^{\text {st }}$ October, 1996 with its capital in Abakaliki by the then military regime of late General Sani Abacha, has boundaries with Enugu State in the North, Benue State in the West, Cross River State in East and Abia State in the South.

What is today called Ebonyi State has come a long way, nearly 40 years ago, when in 1957/58 the initiators of the state movement presented written memoranda and oral evidence to the Wilink's commission of inquiry into the "Fears" of minorities and the means of allaying them.

Ebonyi State's political journey has not only come a long way, but has been a tortuous, thorny and difficult one. Indeed it is test of courage, commitment and respect for justice and truth as well as a proof of the people's will to survive socio-political strangulation.

Ebonyi State like any other state in Nigeria has experienced series of communal clashes over land disputes and natural resources deposits. Currently the state is facing communal clashes with its Cross River State neighbor, at Izzi Local Government Area axis of the state and another communal clash with its Benue State neighbor that is between Ohaukwu of the state and Agila of Benue State. Apart from these, the state is also facing another bloody communal clash of inter-communities within the state over a piece of land with lead deposit. More explicitly, the said communal clash is currently on-going between the people of Enyimbchiri community in Ikwo local government area and the people of Enyigba community in Abakaliki Local Government Area of the state.

Having given the background information of Ebonyi State, which is to make for better understanding or comprehension of the subject matter, it becomes imperative to focus on the utmost aim and interest of this paper which is not to unveil or x-ray the remote and immediate causes of the communal clashes in Ebonyi State of Nigeria, but rather to show how communication could be used to resolve the communal clashes bedeviling the state.

\section{MEANING AND NATURE OF COMMUNAL CLASH}

Before delving fully into the subject matter of this paper which bothers on the communication imperative of resolving communal clashes in Ebonyi State, it is important to first-attempt to define clashes and explain the nature of communal clashes.

The word clash has various meanings which stretch according to use in different disciplines. It may refer to disputes which vary from a bloody skirmish into the choice of news to listen to and television channels to tune to. Clash or conflict connotes disagreement and the failure of the minds of people to agree on certain issues. This can happen 
between two individuals, groups versus groups, an individual versus a group, state versus state, nation versus nation and so on. According to Nwosu (1996), clash is a struggle over value, and claims to scarce status, power and resources in which the aim of the opponents is to neutralize, injure or eliminate their rivals. In this sense clash may be conceptualized as a way of setting problems originating from the opposing interest and from the continuity of the society.

On the other hand, clash could mean to strike together. This suggests that clashing has to do with jamming of one or more things and these two things can be physical. In the context of this paper it is indeed physical. Clash or conflict can also be defined as behaviour between two parties whose interest are or appear to be incompatible or clashing. Clash can equally be defined as a perceived incompatibility of action or goal or as the process in which one party has taken some actions that will exert negative effects on its major interest or is about to take such action.

\section{HISTORICAL BACKGROUND OF COMMUNAL CLASH IN EBONYI STATE}

It is important to identify the nature of the communal clashes in Ebonyi State, having attempted the definition of clash, though not comprehensive. The unending conflicts or clashes ravaging some part of the state are communal clashes. The clashes have escalated to different parts of the State, taking the posture of both inter communal clash and inter-states communal clashes, respectively.

Further explanation of the situations in the state as it concerns various communal clashes show that the intercommunal clash is between the people of Enyibuchiri community in Ikwo Local government area and their neighbouring community of Enyigba in Abakaliki local government area. The crux of the matter centres on land space. The two warring communities lay claims to a portion of land with natural resources, including lead and salt.

The crisis which began sometime in May, 2017 had continued despite some efforts and steps taken to bring it to an end. The lingering crisis which engulfed the two communities has only not consumed human lives, but has destroyed a lot of property including farms and livestock. Most recently, a family of about twelve who attended the matriculation ceremony of their daughter was ambushed by their opponents from the other community and all of them were killed, leaving only the newly matriculated student who did not come back with her family members.

On the other hand, the other communal clashes in the state are between the people of Ngbo in Ohaukwu local government in Ebonyi State and Agila community in Benue state over Territorial boundary. According to the parties in dispute, there have been accusations and counter accusation of boundary violations.

Similarly, there is also another communal bloody clash going on as a matter of territorial boundary alleged violation between the people of Igbeagu community in Izzi local government area of Ebonyi State and the Ukele community in Iyala Local Government Area of Cross River State. These communal clashes have incurred huge losses both in human and material resources from the parties involved in the communal clashes.

Despite clarion calls by different individuals and groups to the communal clash in the state, it is rather becoming endemic. Every community in the state groans under acrimonious communal clash without a commitment to resolving it. It would appear that it has come time, according to former war-time UK Prime Minister, Winston Churchill's statement at a White House luncheon, June 26, 1954, to jaw-jaw [talk] than to war-war [fight].

Virtually all wars end at the negotiating table. Therefore communication should be emphasized and could be used as a means to resolve communal clashes in Ebonyi State. When this is urgently done it will promote peaceful and harmonious co-existence of the communities in Ebonyi and by extension-usher in healthy development and progress in the state in particular and its neighbouring states, in general.

\section{ORIGIN AND DEVELOPMENT OF COMMUNICATION}

Communication as we know it today has developed over a number of centuries. The sophistication and complexity which characterize human communication in the modern world are the result of a very long and sustained effort by human beings to improve on one of the most fundamental aspect of their existence. According to MacBride commission as the world has advanced, the task of communication has become more complex. In explaining this complexity, MacBride and his colleagues (MacBride, 1981) have this to say:

Throughout history, human beings have sought to improve their ability to receive and assimilate information about their surroundings and at the same to increase the speed, clarity and variety of their methods for transmission of information. 
Communication is as old as humanity. The first human beings to inhabit the earth lived in caves; they looked and behaved more like apes. Even during those pre-historic times, some form of communication existed. Before the development of languages, this communication was mostly through touch and vocal signals. The development of language was a turning point in the evolution of communication. Language made human communication powerful and saved human beings their pre-eminent position in the animal world. From inception communication has been related to social structure, culture and the economic organization of the society. Because of this, communication has all through the ages been an inescapable part of the existence of human beings as social animals. In fact, communication is indispensable to human existence. According to Bittner (1980), society's survival and growth depended on a number of things among them a system of communication.

\subsection{Defining Communication}

Communication has been defined in many ways by various people: Jayaweera (1991) defines communication as an interaction process through which persons or group relate to each other and share information, experiences and culture. To communicate basically means to share ideas, information, opinions feelings or experience between people. The basis of communication is this sharing or exchange between the people involved in any communication process, before communication can be effective. As a matter of fact, the word communication is derived from "communism" which is a Latin word meaning common. Schramm (1954), points out that when people communicate they are trying to share information, an idea or an attitude.

\subsection{Components of the Communication Process}

The communication process is an exchange or a sharing of information or a message. It needs certain basic component to bring it into existence these include:

The source from whom the message originates. The medium through the message is conveyed. The audience who receives the message; the feedback which is the reaction of the receiver to the message.

\section{THE ROLE OF COMMUNICATION IN RESOLVING COMMUNAL CLASHES IN EBONYI} STATE

The role of communication cannot be over emphasized in resolving communal clashes. The mere presence of communal clashes does not have to be the death knell of the parties involved. In view of this, we are concerned here with the communication imperative in resolving the persistent communal clashes in Ebonyi State. Accordingly, we look at some of the ways that communication could be used in resolving communal clashes in Ebonyi State. These are as follows:

- Bringing together different groups or parties in the dispute to discuss issues: Communication is the cement that holds society together. What is to be done therefore in communal clashes is to bridge the gap arising between two feuding parties by getting the parties to talk. The media can play effective role as a tool to build relationships among warring communities in Ebonyi state. It could lend support to greater understanding between the people who have considered themselves different from one another. It can equally serve as a mediator between the members of the communities in dispute since communication is the most effective instrument of making peace particularly now there are ongoing communal clashes and ensure post-conflict reconciliation.

- Provision of media outlet for expression: The media through communication could provide platform through which the warring communities in Ebonyi state will express their fears, frustrations and share experiences with others.

- Increasing knowledge of complex issue: The communities that are involved in communal clashes are mainly rural communities or dwellers who are not well-educated. Therefore, some of their actions emanate from their lack of knowledge to the law. On this basis, the media through communication should educate and increase their knowledge on the consequences of any unlawful action taken. It can help them to critically think about and discuss some issues that directly affect their lives. Research has shown that people, who were exposed to BBC media actions on various discussion shows knew more, discussed more and participated more in matters of interest, even when controlling factors that may influence these outcomes are not there. So when they have good knowledge of the law, they would see reason to lay down their arms and sue for peace through negotiations.

- Motivation for peace: Peace is a panacea for development and emancipation. The media through vigorous communication should carry campaign of peace, understanding as well as love to motivate people from the 
crisis areas in the state to participate in community events. The media should work on their attitudes and opinions that would shape their behaviour to have a rethink.

- Adequate information to the communities at war: Lack of proper communication or information can at any stage of a conflict, make people desperate, restless and easily manipulated. Accordingly, it is imperative that the media should package positive information or communication that would strength their decision to negotiate for peace. Such communication should dwell on their economic growth, democratic structures and the positive outlook of their future. This would definitely give them relief and hope and the idea of resolving the matter that led to the communal clash.

- Broadcasting of news by using the community radios: This can to a large extent reach the communities at war in Ebonyi state who are scattered in different parts of the state. This will be achieved by using different languages of the people. Through this the people can be adequately addressed directly and their own personal experience and lives can be in-corporated much better than with foreign media. Another advantage of this local media, especially the radio is that in boarder areas it is possible to convey peace messages to passing fighters and refugees alike in Ebonyi state. It is vital that the use of information or communication within a society is not solemnly passive, but that the population in these communal clashes gets actively involved in creating content. So with this, communication would have performed a vital role in the resolution of the communal clashes in some part of Ebonyi state.

- Using communication as an instrument for mobilization and participation for peace: Communication is central to all human activities. It is a potent weapon that thickens the society or reduces it to nothingness depending on the intent of the sender. Whatever is the societal problems or programme, be it resolution to crisis or politics, mobilizing for participation by way of soliciting for smooth and peaceful behaviour to participate in the process of reconciliation, depends on communication. According to MacBride (1980), communication is a powerful instrument all over the world and the relationship between peace and communication is an indissoluble one. When we communicate, we are trying to establish commonness with someone, groups, society and to share information, ideas or attitudes, sensitize and mobilize. Therefore, communication could be used as an instrument of mobilization for peace and resolution to the communities involved in communal clashes in Ebonyi State. This is because the act of mobilizing people into action depends largely on the knowledge obtained from enlightenment for peace and understanding. Mobilization increases the participation of people in any social issues; it brings everyone qualified to make peace and people are involved in the process of resolution of crisis. It is pertinent here to note that in achieving permanent resolution in various communal clashes ravaging Ebonyi State, the stage should first be ready to indicate readiness by the parties involved for making peace. Then to achieve this, depends on the level of mobilization exerted on them by the mass media through communication to ensure greater participation of the people. In ensuring this, the mass media should make use of persuasive words to evoke sufficient attention, while packaging the message to help reduce the psychological resistance of the people to embracing peace. So, the degree to which they accept the appeals for reconciliation are based on the motivational appeals presented during the enlightenment and persuasion campaign. This comes in the form of public speech at their gathering and media programmes.

- Peace journalism: This is also a powerful mechanism that would be deployed to demonstrate the communication imperative in resolving communal clashes in some parts of Ebonyi State. To effectively do this, it implies that peace journalists should endeavour to uncover the causes behind the clashes and true goals of all participants while making sure to humanize all victims of the conflict. The journalists should not bother to exploit the losses and sufferings incurred due to the misunderstanding, but ensure that his reports are balanced. Part of his mandate or ethnical guidelines for this kind of reporting should be to bring out people that are willing, use peaceful measures and speak out against communal clashes and violence as well as do documentaries on the suffering and losses on both sides. So with this measure of peace-building, the process of resolving communal clashes would be enhanced, as some concerned participants would see reasons why peace should be allowed to reign among them for their own benefit and that of their children.

- Communication based on Negotiation: This is another strategy to be used in resolving community and inter states communal clashes in some parts of Ebonyi State. It consists basically of discussion or communication between both parties in dispute and their allies with a view to reconciling divergent 
opinions or views or at least, understanding the differing positions of the stakeholders. It does not involve any third party. The parties concerned decide among themselves how best to resolve their differences through interpersonal communication methodology.

- Negotiation will involve communication, discussions, and arguments with the hope of resolving the crisis. It is by this communication, mutual discussions and understanding that the remote causes of crisis in the state will be revealed and the opposing contentions elucidated. Thus communication is the most satisfactory strategy used in resolving community conflict because the parties are directly involved. They continue to communicate and discuss on the issue until the conflict will be resolved.

- Adopt Empathic Communication Strategy: This is a very effective technique of using communication to resolve crisis. This means putting oneself in another person's shoes. What it implies here is that in applying this strategy of communication to the resolution of crisis in Ebonyi State, the communicator should consider the target audience of the communities in dispute before himself. This will certainly help him to communicate in a manner that will make it impossible to be misunderstood by the members of the concerned communities at war. It will also help him, the communicator to be a good listener in the communication process aimed at engendering peace and permanent resolutions of the communal clashes.

\section{CONCLUSION}

We have attempted in this discourse to have an overview of communal clashes or conflicts as well as communication as imperative in resolving communal clashes in Ebonyi State, Nigeria. A clear understanding of the powers of communication could help in applying it in resolving communal conflicts as is the case in Ebonyi State, Nigeria.

The communication strategies explained in this discourse is certainly a product of a thorough and detailed research. So with the application of these to the communal clashes devastating some parts of Ebonyi State we should be on our path to peace, understanding, and permanent resolution of the crisis as well as peaceful co-existence of the concerned communities.

The key factors that influence the success or failure of communication in resolving crisis in a particular area at any given time depends on the techniques or strategies adopted by the communicators. Therefore to avert such failure in demonstrating the communication imperative in resolving communal clashes in the state, the communicators should fully apply the strategies aforementioned earlier in this paper.

\section{REFERENCES}

Bittner, J.R. (1980). Mass Communication: An Introduction: Englewood Cliffs: Prentice-Hall

Jayaweera, N. (1991) Folk media and development communication - myths and realities: a report on experiences in people's communication in Mexico, India, and the Philippines, Asian Social Institute (Manila)

MacBride, S. (1981), May voiles, one world (Nigerian Edition), Ibadan: Ibadan: Ibadan University Press.

Nwosu, Ikechukwu (1996), Mass Media and African wars: Media images of crisis of crisis in Africa, Enugu: Star Printing and Publishing Company.

Onigu Otiti (1999), Community conflicts in Nigeria, Ibadan: Spectrum Book Limited

Oshita, O. \& Osaze, B. (2010). Conflict, equity and resource capture in Africa: The Nigerian experience. in conflict resolution, identtity crisis and development in Africa: Malthouse Press Limited.

Schramm, W. (1954). How communication works. In W. Schramm (Ed.), The process and effects of mass communication. Urbana, IL: University of Illinois Press.

White, A. (216), Media Ethics in a context of war or conflict: A discussion paper for International Media Support 